\title{
Radiological impact assessment of different building material additives
}

\author{
E. Kocsis ${ }^{1} \cdot$ E. Tóth-Bodrogi ${ }^{1} \cdot$ A. Peka ${ }^{1} \cdot$ M. Adelikhah ${ }^{1} \cdot$ T. Kovács $^{1}$ (I)
}

Received: 4 May 2021 / Accepted: 8 July 2021 / Published online: 27 July 2021

(c) The Author(s) 2021

\begin{abstract}
In this study, samples of building material additives were analyzed for naturally occurring radioisotope activity such as uranium, radium, and radon. The radon exhalation and the annual effective doses, were also calculated. The activities of the samples, were determined using HPGe gamma spectrometry and ionization detector. The results were used to calculate dose values by using RESRAD BUILD code. The activity concentration of the samples ranges between 9-494 Bq/kg Ra-226, 1-119 Bq/kg Th-232 and 24-730 Bq/kg K-40. In conclusion the investigated samples can be used safely as building material additives as they do not pose a major risk to humans.
\end{abstract}

Keywords Gamma-spectrometry $\cdot$ By-product $\cdot$ Building material $\cdot$ Radon $\cdot$ Absorbed dose

\section{Introduction}

Some industrial raw materials contain significant concentrations of natural radionuclides, these are naturally occurring radioactive materials (NORM), which are widely used in the production of some building materials, like Portland cement, concrete, bricks and so on [1-3]. In case of using this kind of material as additives in different kind of construction materials, the construction sector will fulfill two main environmental criteria. First, the reduction of the needed natural resources in the building process as raw materials, and second, minimizing the emission of some air pollutants like $\mathrm{CO}_{2}, \mathrm{NO}_{2}, \mathrm{NO}_{3}, \mathrm{SO}_{2}$, etc. $[4,5]$. This is a great opportunity, to reuse industrial by-products, even in the case of the NORM materials, like additives used in the construction industry [5]. Nowadays, more and more studies are dealing with finding the most environmental friendly materials and also methods, which can be used for different kind of building purposes [3, 6-8, 10, 11]. Most of the population spends about $80 \%$ of their time indoor. This is why the knowledge about natural radiation becomes more and more important these days. The activity concentration of building materials containing NORM materials contribute in two ways to the

T. Kovács

kt@almos.uni-pannon.hu

1 Institute of Radiochemistry and Radioecology, University of Pannonia, Veszprém, Hungary increased radiation exposure [12,13]. First of all, there is the external body dose exposure mostly coming from K-40, U-238, Th-232 and their decay products. Beside the external radiation dose, we have to mention the second contributor, the internal radiation dose [14]. The radon exhalation contributes to the increasing of the internal dose, especially through its progeny. Radon decay products easily can enter into the human respiratory system, where due to their alpha and beta emitter properties, they can cause some serious damage [15-17]. As we already mentioned, building materials can increase the dose rate. Especially when they contain different kinds of relatively high activity concentration byproducts, from various industries. These by-products can come from different sources, such as coal-fired power plants, alumina production by-products or from the phosphate fertilizer industries [18]. The average of indoor absorbed dose rate in air from terrestrial sources of radioactivity is estimated to be $84 \mathrm{nGy} / \mathrm{h}$ according to the UNSCEAR 2000 report [19].

In this work, the concentrations of natural radionuclides have been measured in nine samples, which can be potentially used in the construction industry. The measurements have been carried out with a high purity germanium gamma detector, with the aim to assess the radiological hazards due to external gamma ray exposure in dwellings. The potential radiological hazards of these materials were determined by calculating the indoor absorbed gamma dose rate $\left(D_{R}\right)$, the annual effective dose rate $\left(\mathrm{H}_{\mathrm{R}}\right)$ and the activity utilization 
index I. The obtained results were compared to the recommended values to determine the radiation hazards to humans [20].

\section{Experimental}

In this study nine different samples were measured, all of which can be used in the construction industry, including raw primary materials (coal, clinker, limestone), by-products (red mud, fly ash, slag, mill tailing) and construction materials (cement, gypsum). The samples were transferred to the laboratory to perform the measurements, where first the samples were dried until constant weight in an oven. After that we grinded the samples under $0.63 \mathrm{~mm}$. The samples were transferred into a leak-proof Marinelli beaker, weighted, hermetically sealed and stored during 27 days, to achieve the secular equilibrium between Ra-226 and its progeny.

\section{Gamma-spectrometry}

The activity concentration of Ra-226, Th-232 and K-40 was determined by using a semiconductor HPGe detector (ORTEC GMX40-76 with an efficiency of 40\%). The activity concentration of the various radionuclides were calculated by using the gamma energy lines of their progeny elements, the $296(18.5 \%) \mathrm{keV}$, and $351(37.1 \%) \mathrm{keV}$ lines from $\mathrm{Pb}-214,609$ (46.1\%) keV and 1120 (15\%) keV lines from $\mathrm{Bi}-214$ were used to determine Ra-226. activity concentration. To determine Th-232 activity concentration we used the gamma lines of 583 (86\%) $\mathrm{keV}$ and 2614 (35.8\%) keV from Tl-208 and 911 (29\%) keV from Ac-228. For K-40 we used its own gamma line at $1460(10.7 \%) \mathrm{keV}$.

Before the sample measurements were made, the environmental gamma background was measured, with an empty Marinelli sample holder, under the same measurement conditions. The measurement time for each sample was 80 $000 \mathrm{~s}$. The detector efficiency calibration was determined by using an IAEA soil reference material. The detection efficiency separately for Ra-226, Th-232 and K- 40 were $2.42 \%$, $1.4 \%$ and $1.2 \%$, respectively. The detection limits were 23.0 , $0.7,0.5$ and $23.0 \mathrm{~Bq} / \mathrm{kg}$, respectively.

\section{Exhalation rate and emanation factor}

One of the main sources of indoor radon is the used building materials. Radon can accumulate indoor due to the exhalation from the building materials being closed inside. This is why the radon exhalation in the used inbuilt materials should be kept as low as it is possible. The mass and the surface exhalation rate for all the samples were determined. All the samples were prepared, and $0.1 \mathrm{~kg}$ of them was closed hermetically in a gas accumulation chamber. The chamber is equipped with a small size fan, which ensures the homogeneous inert air in the chamber. Before the measurements were started, the accumulation chambers were purged with nitrogen gas, to ensure that at the moment of closing the samples, there was no additional radon concentration present in them. The radon activity concentration in the accumulation chambers were determined by using an AlphaGUARD 2000 portable radon monitor after the appropriate waiting period.

The whole measurement system is a closed circular system, which contains an accumulation chamber, an AlphaGUARD radon monitor, and a pump, which makes the air full of radon circulate in the system. The volume of the detectors ionization chamber is $0.56 \mathrm{dm}^{3}$, and the whole measurement system has a volume of $1.44 \mathrm{dm}^{3}$.

$E_{\text {mass }}=\frac{C * V}{m * t} * \frac{\lambda * t}{1-e^{-\lambda * t}}$

After turning on the AlphaGUARD, the measurement mode has been selected, which was the"10 min FLOW" mode. After setting the right mode, we turned on the radonproof pump for $10 \mathrm{~min}$, in this time the air containing radon circulates in the whole volume of the system. In the first 20 min of the measurement we get not just the signal from the radon activity concentration; we get the signal from thoron too. The detector we used (AlphaGUARD 2000) cannot separate the two isotopes, so in this case we stopped the airflow in the system so we can obtain just the radon activity concentration in the remaining measurement time. The measurement time period for each sample in between 30 and $60 \mathrm{~min}$. The value of exhalation was calculated by the following equation [21]:

where, $\mathrm{E}_{\text {mass }}$ is the mass exhalation rate $[\mathrm{Bq} / \mathrm{kgh}], \mathrm{C}$ is the accumulated Rn-222 concentration $\left[\mathrm{Bq} / \mathrm{m}^{3}\right], \mathrm{V}$ is the volume of the system $\left[\mathrm{m}^{3}\right], \mathrm{m}$ is the mass of the sample $[\mathrm{kg}], \lambda$ is the decay constant of Rn-222 [1/h] and t is the accumulation time [h].

\section{Activity Concentration Index (I-index)}

The Council Directive 2013/59/Euratom defines that in case of building materials, we need to define the activity concentration index, the I-index, in order to qualify and regulate the gamma radiation exposure originating from the radionuclides inside of the building materials. The I-index can be calculated using the following equation [20, 22, 23]:

$I=\frac{C_{R a-226}}{300}+\frac{C_{T h-232}}{200}+\frac{C_{K-40}}{3000}$

where, $\mathrm{C}_{\mathrm{Ra}}, \mathrm{C}_{\mathrm{Th}}$ and $\mathrm{C}_{\mathrm{K}}$ denotes the activity concentrations of Ra-226, Th-232 and K-40 (Bq/kg), respectively. The value 
of the I-index can be used as a screening tool to identify those materials what exceed the reference value of 1 .

\section{Absorbed dose rate (D) estimation}

By using the dose conversion factors of $0.92,1.1$ and $0.080 \mathrm{nGy} / \mathrm{h}$ per $\mathrm{Bq} / \mathrm{kg}$ for radium, thorium and potassium the dose can be calculate by using the following equation:

$D=\left(0.92 * A_{R a-226}\right)+\left(1.1 * A_{T h-232}\right)+\left(0.080 * A_{K-40}\right)$

where, $\mathrm{D}$ is the gamma dose rate from natural radionuclides (nGy/h), and $A_{\mathrm{Ra}-226}, \mathrm{~A}_{\mathrm{Th}-232}$ and $\mathrm{A}_{\mathrm{K}-40}$ are the activity concentrations of Ra-226, Th-232 and K-40 (Bq/kg), respectively. These can be used to calculate the total absorbed dose gamma rate in air, above $1 \mathrm{~m}$ from the ground [19].

\section{Annual effective dose estimation (AED)}

To determine the annual effective dose we must use the conversion coefficient for the absorbed dose in the air ( $0.7 \mathrm{~Sv} / \mathrm{Gy})$, and the indoor occupancy factor. Nowadays most people spend $80 \%$ of their time indoor, and $20 \%$ outdoor. The annual indoor effective dose was calculated using the following equation $[17,24,25]$ :

$A E D(m S v)=D * 8760 * 0.8 * 0.7 * 10^{-6}$

\section{The use of RESRAD-BUILD code for simulation}

For a radiological assessment of the indoor exposure we used the program code called RESRAD-BUILD [26]. By using this code, we can estimate the risk to inhabitants who live in a building which contains a significant amount of NORM material in their walls [26]. In this study, the program code was used to determinate the radiological risk due to indoor exposure for a resident in different long-term occupancy scenarios, with different room dimension and wall thickness parameters. Previous studies like Sundal et al. 2004 [27] show us that the building properties like wall thickness, and room area can significantly change the external and the radon dose and the total annual dose values. In this study the proposed model room was built from concrete, with different compositions; mixtures of cement, red mud, fly ash and mill tailing with different percentages. These were those materials which had the highest amount of radioactive isotope content in the samples, this is why we choose them, to determinate the possible risks.

In this study the room dimensions and the wall thickness was changed, in order to show the influence of these parameters to the external dose, the radon dose and the annual dose. The calculations were started with a room model of $4 \times 4 \times 4 \mathrm{~m}$, where in this case it was assumed just one inhabitant. In this study can be seen multiple different case studies. In the first case it was modified the room area from 16 to $48 \mathrm{~m}^{2}$ in 5 steps. The wall thickness and the air exchange rate was not changed, the value of them remained $0.2 \mathrm{~m}$ and $0.8 \mathrm{~h}^{-1}$ respectively. In the second case it was modified the wall thickness values from 0.05 to $0.5 \mathrm{~m}$. The room area and the air exchange rate were the same, respectively $16 \mathrm{~m}^{2}$ and $0.8 \mathrm{~h}^{-1}$. Some important parameters like concrete density, radon emanation, and indoor fraction remained the same, given by the RESRAD BUILD program code, respectively $2.35 \mathrm{gcm}^{-3}$, 0.2 and 0.8 . In every case the receptor is located in the middle of the room.

\section{Results and discussion}

\section{Gamma spectrometry results}

The activity concentration of the studied raw materials ranges between $9 \pm 0.6 \mathrm{~Bq} / \mathrm{kg}$ and $494 \pm 25 \mathrm{~Bq} / \mathrm{kg}$ for $\mathrm{Ra}-226,1 \pm 0.1 \mathrm{~Bq} / \mathrm{kg}$ and $119 \pm 8 \mathrm{~Bq} / \mathrm{kg}$ for Th-232 and in case of K-40 the activity concentration ranged between $24 \pm 1 \mathrm{~Bq} / \mathrm{kg}$ and $730 \pm 28 \mathrm{~Bq} / \mathrm{kg}$. The activity concentration results can be seen in Fig. 1. Some of the measured samples have higher activity concentrations than the world average radionuclide activity concentrations in soils reported in the Radiation Protection 112 report [24], where the average activity concentration value for Ra-226 and Th-232 is $50 \mathrm{~Bq} / \mathrm{kg}$ and for $\mathrm{K}-40$ is $500 \mathrm{~Bq} / \mathrm{kg}$ [24] (Table 1).

The obtained activity concentrations results were compared with Ra-226, Th-232 and K-40 activity concentrations in the same type of samples from other European countries, except the tailing samples, those were compared with South African data. All of the obtained values fit in the range of the other countries measured data [28-30].

The result of the measured radionuclides in the samples indicate that some of the materials could be considered harmful to the residents in long therm. Long-term exposure for those materials containing a high content of radium could cause different health issues, like lung cancer. Thus, to evaluate the possible risk, the radiological hazard indexes are presented in Fig. 4.

\section{Exhalation and emanation results}

The radon mass exhalation values range between $0.07 \pm 0.004$ and $0.11 \pm 0.007 \mathrm{~Bq} / \mathrm{kgh}$ and the surface exhalation ranges between $1 \pm 0.096$ and $2 \pm 0.15 \mathrm{~Bq} / \mathrm{m}^{2} \mathrm{~h}$ with an average value of $0.08 \pm 0.004 \mathrm{~Bq} / \mathrm{kgh}$ for mass exhalation and $1 \pm 0.1 \mathrm{~Bq} / \mathrm{m}^{2} \mathrm{~h}$ for surface exhalation. The highest mass and surface emanation has been measured in the mill 
Fig. 1 Ra-226, Th-232, K-40 activity concentration values in the measured samples
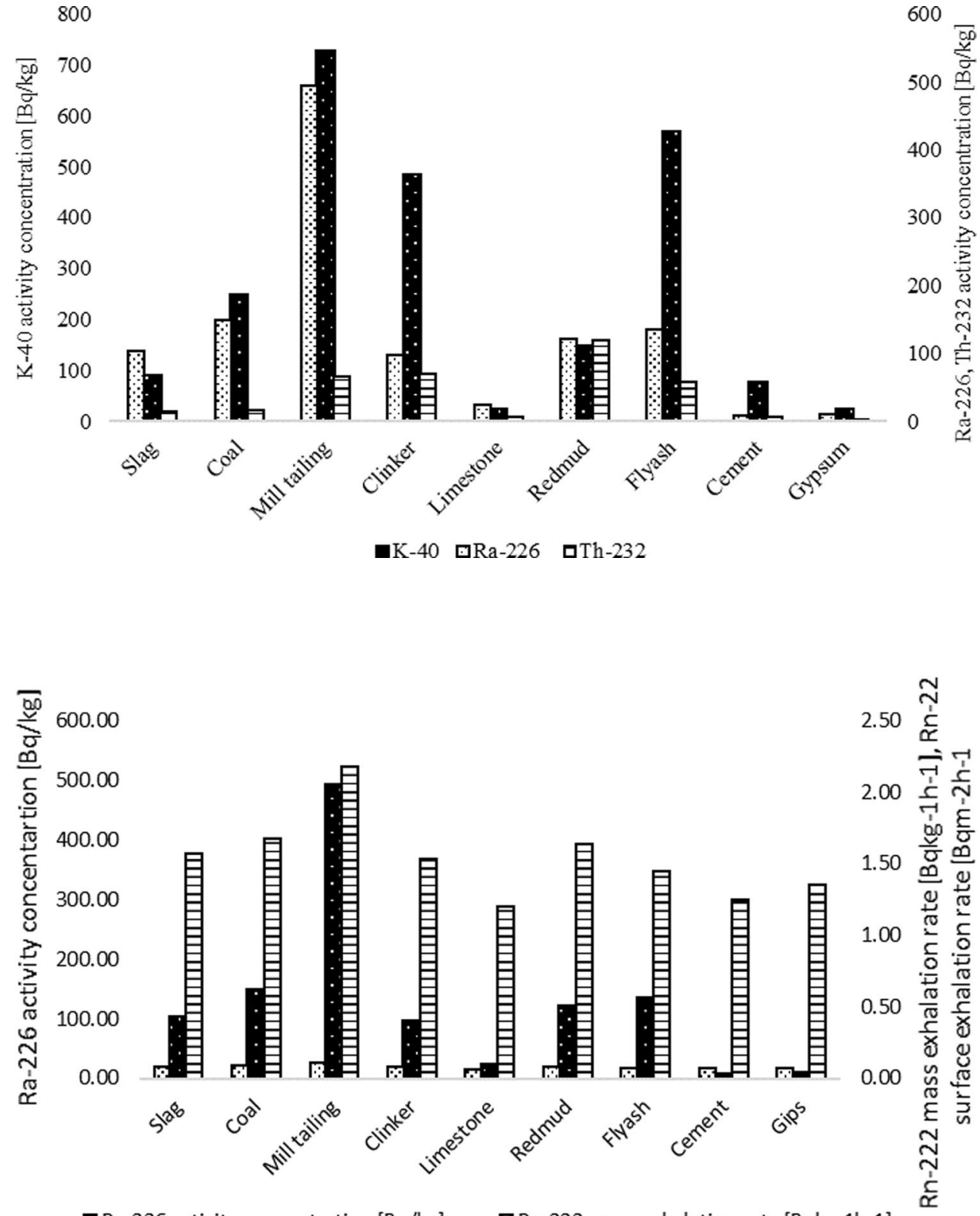

- Ra-226 activity concentartion $[\mathrm{Bq} / \mathrm{kg}] \quad \boldsymbol{Q} \mathrm{Rn}-222$ mass exhalation rate [Bqkg-1h-1]

日Rn-222 surface exhalation rate [Bqm-2h-1]

\begin{tabular}{lllccc}
\hline Sample & & Ra-226 [Bq/kg] & Th-232 [Bq/kg] & K-40 [Bq/kg] & \\
\cline { 1 - 2 } Primary raw materials & Coal & $68-1391(149)$ & $14-100(16)$ & $200-500(250)$ & {$[28]$} \\
\hline \multirow{2}{*}{ By-products } & Clinker & $29-316(98)$ & $30-537(69)$ & $412-2521(485)$ & {$[28]$} \\
& Limestone & $3-79(23)$ & $1-19(6)$ & $5-18(24)$ & {$[28]$} \\
& Red mud & $97-301(122)$ & $118-539(119)$ & $50-215(148)$ & {$[28]$} \\
& Fly ash & $75-815(136)$ & $37-140(58)$ & $157-900(569)$ & {$[28]$} \\
& Slag & $15-336(104)$ & $1-152(15)$ & $20-786(92)$ & {$[28]$} \\
Construction materials & Mill tailing & $87-2668(494)$ & $20-89(66)$ & $226-781(730)$ & {$[29]$} \\
& Cement & $4-422(9)$ & $3-266(6)$ & $4-846(78)$ & {$[30]$} \\
& Gypsum & $1-70(11)$ & $1-100(1)$ & $5-279(26)$ & {$[30]$} \\
\hline
\end{tabular}


Table 2 Pearson's correlation coefficient results between radiological parameters

Ra-226 activity concentration $\quad \mathrm{Rn}-222$ mass exhalation rate

$[\mathrm{Bq} / \mathrm{kg}] \quad[\mathrm{Bq} /(\mathrm{kgh})]$
Rn-222 surface exhalation rate $[\mathrm{Bq} /$ $\left.\left(\mathrm{m}^{2} \mathrm{~h}\right)\right]$
Ra-226 activity concentration $[\mathrm{Bq} / \mathrm{kg}]$

$\mathrm{Rn}-222$ mass exhalation rate $[\mathrm{Bq} /(\mathrm{kgh})]$

$\mathrm{Rn}-222$ surface exhalation rate $\left[\mathrm{Bq} /\left(\mathrm{m}^{2} \mathrm{~h}\right)\right]$
1

$0.945-1$
1 are shown in Table 2. A strong positive and statistically significant correlation is observed between Ra-226 activity concentration and the Rn-222 mass and surface exhalation rates (Table 3 ).

In Fig. 3 a-b we can see the correlation between the radium concentration and the two different radon exhalation rates of the source material. The positive correlation can be easily observed between radium concentration values and the mass $\left(R^{2}=0.9\right)$ and surface exhalation $\left(R^{2}=0.9\right)$ results. The relationship between the activity concentration results of radium and the mass and surface exhalation values are shown to be linear [37].

\section{Radiological hazard indices of the materials}

\section{Annual effective dose rate results}

The recommended limit value by the ICRP for the annual effective dose is $1 \mathrm{mSv} /$ year for the public. The calculated values range between 0.08 and $3.6 \mathrm{mSv} /$ year. Five of the measured samples exceed the $1 \mathrm{mSv} /$ year recommendation

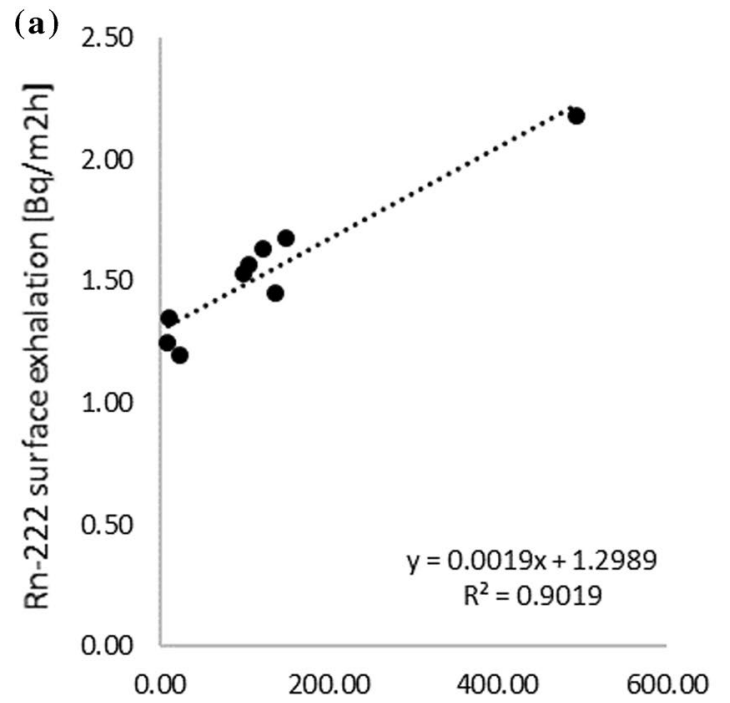

Ra-226 activity concentration $[\mathrm{Bq} / \mathrm{kg}]$

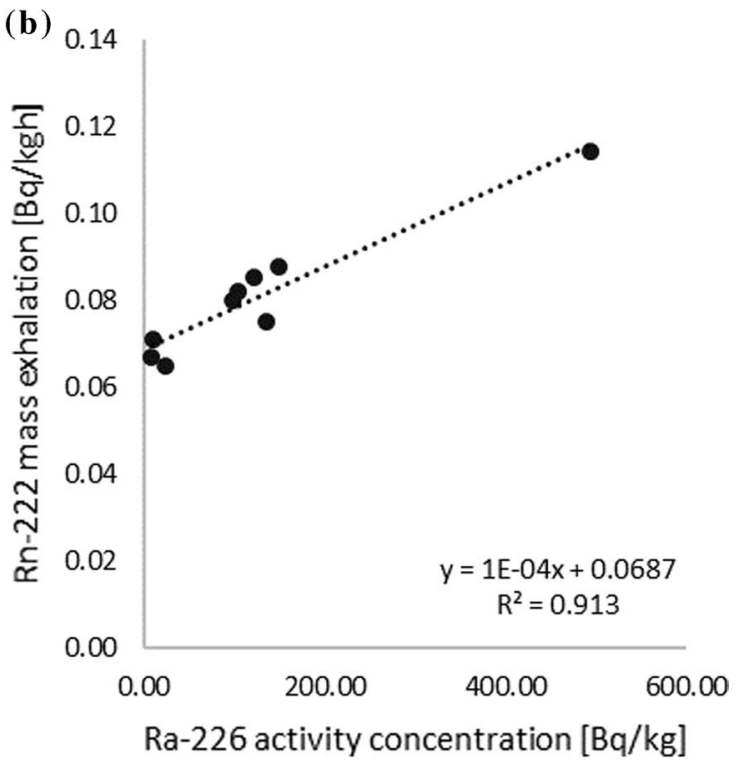

Fig. 3 Correlation between radium activity concentration $[\mathrm{Bq} / \mathrm{kg}]$ and surface exhalation $\left[\mathrm{Bq} / \mathrm{m}^{2} \mathrm{~h}\right]$ values a and Correlation between radium activity concentration $[\mathrm{Bq} / \mathrm{kg}]$ and mass exhalation $[\mathrm{Bq} / \mathrm{kgh}]$ values $\mathbf{b}$ 
limit, the highest value was measured in the mill tailing sample, with a value of $3.6 \mathrm{mSv} /$ year.

\section{Activity Concentration Index (Index-I) results}

According to the performed measurements, most of the studied materials can be used as additives in building materials in huge amounts. In these cases, the Index-I of the additive is lower than the recommended value of 1, adding it won't raise the Index-I of the final product above 1, so the additional effective dose won't be higher than $1 \mathrm{mSv} /$ year. These kinds of materials can be used as additives in concretes or bricks in unlimited amounts from a radiological perspective. Two of the measured materials exceeded the value of 1 , these are the mill tailing and the red mud. In his case the calculated I-index is higher than 1 , due to this, these materials can be use in the construction industry but in smaller amounts like the other materials, and they cannot be used like additional materials in building construction materials (e.g., brick, concrete).

Although, the radiological hazard indexes do not greatly exceed the recommended values, it is suitable to monitor the radiological content of the chosen building material before using it in the construction industry, and the use of additives with high Index-I values must be limited to stay under the recommended values. The radiological hazard indices can be seen in Fig. 4.

\section{RESRAD BUILD simulation results}

Since most of the residents spend $80 \%$ of their time indoor [17], the natural radioactivity coming from the walls, floor and ceiling could affect them in a significant way. The expected activity concentrations of Ra-226, Th-232 and
Table 4 The radionuclide concentrations and the activity concentration index (Index-I) of concrete mixtures

\begin{tabular}{lcccl}
\hline Sample & Ra-226 & Th-232 & K-40 & Index-I \\
\hline Concrete 1 & 9 & 6 & 78 & 0.1 \\
Concrete 2 & 122 & 199 & 148 & 1.5 \\
Concrete 3 & 65 & 102 & 113 & 0.8 \\
Concrete 4 & 130 & 21 & 241 & 0.6 \\
Concrete 5 & 136 & 58 & 569 & 0.9 \\
Concrete 6 & 72 & 32 & 323 & 0.5 \\
Concrete 7 & 69 & 67 & 218 & 0.6 \\
Concrete 8 & 154 & 67 & 320 & 0.9 \\
\hline
\end{tabular}

$\mathrm{K}-40$, the activity index of the different concrete mixtures for eight different mixing scenarios can be seen in Table 4 . The activity concentration in the mixtures ranges between $9-154 \mathrm{~Bq} / \mathrm{kg}$ for Ra-226, 6 - $199 \mathrm{~Bq} / \mathrm{kg}$ for Th-232 and $78-569 \mathrm{~Bq} / \mathrm{kg}$ for K-40. The materials are called concrete because of the underlying dose estimation models, not all mentioned mixtures would produce viable concrete, however there are other methods for producing building materials, for example sintered ceramics with up to $100 \%$ red mud content.

The activity concentration result shows us that the use of different additives like red mud, fly ash and mill tailing could increase the activity concentrations of the mixtures. The composition of the concrete mixtures in the different scenarios can be seen in Table 5 .

It can be seen that if the amounts of the additives are chosen well the Index-I remains below 1. According to the performed measurements, in the mixture called Concrete 2 , containing just red mud, the radium activity concentration is exceeded, with $11 \%$ and the Index-I is also above the recommended limit.
Fig. 4 Radiological hazard indexes of the measured samples

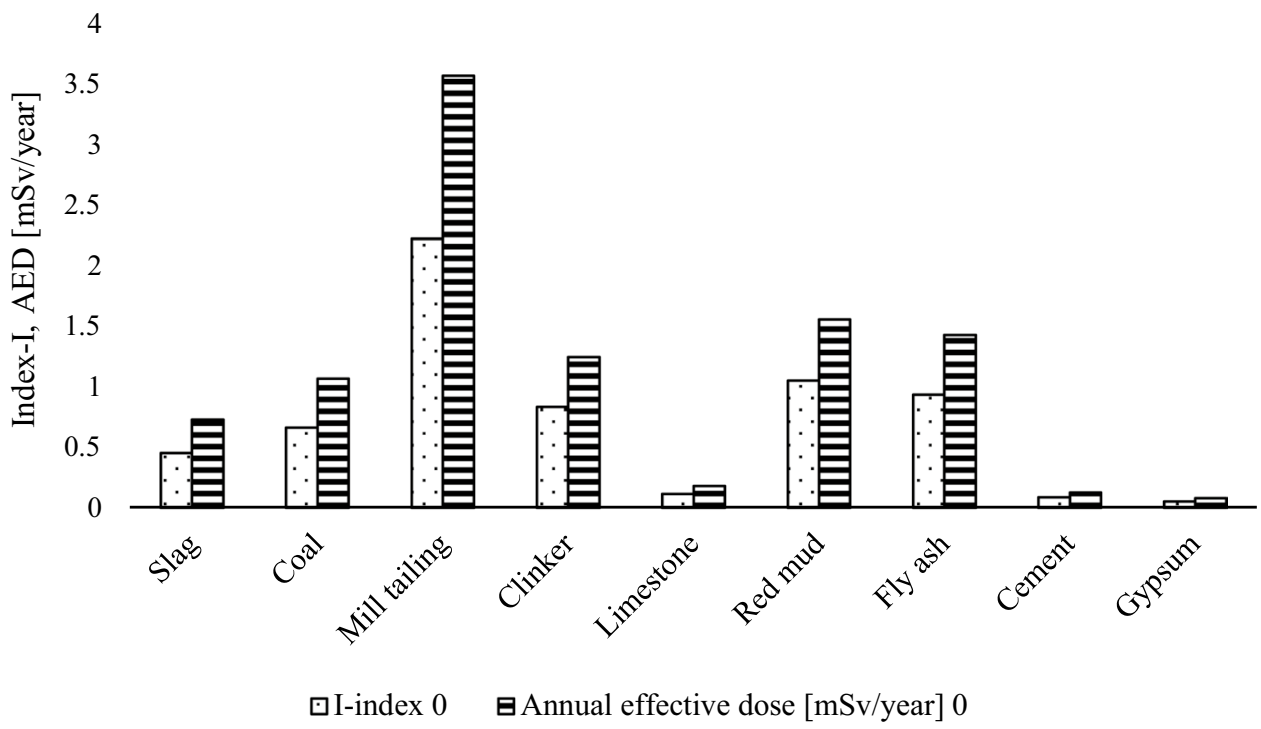


Table 5 The composition of the concrete mixtures

\begin{tabular}{|c|c|c|c|c|c|c|c|c|}
\hline & Concrete 1 & Concrete 2 & Concrete 3 & Concrete 4 & Concrete 5 & Concrete 6 & Concrete 7 & $\begin{array}{l}\text { Con- } \\
\text { crete } 8 \\
(\%)\end{array}$ \\
\hline Cement & $100 \%$ & - & $50 \%$ & $75 \%$ & - & $50 \%$ & $50 \%$ & 40 \\
\hline Red mud & - & $100 \%$ & $50 \%$ & - & - & - & $25 \%$ & 20 \\
\hline Fly ash & - & - & - & - & $100 \%$ & $50 \%$ & $25 \%$ & 20 \\
\hline Mill tailing & - & - & - & $25 \%$ & - & - & - & 20 \\
\hline
\end{tabular}

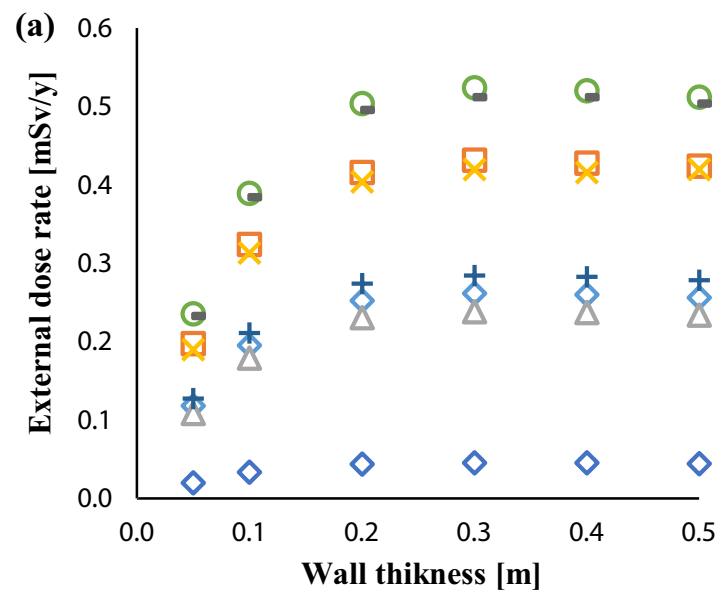

$\diamond$ Concrete_5 $\square$ Concrete_2 $\triangle$ Concrete_3xConcrete_4

- Concrete_6 6 - Concrete_7 - Concrete_8 80 Concrete_1

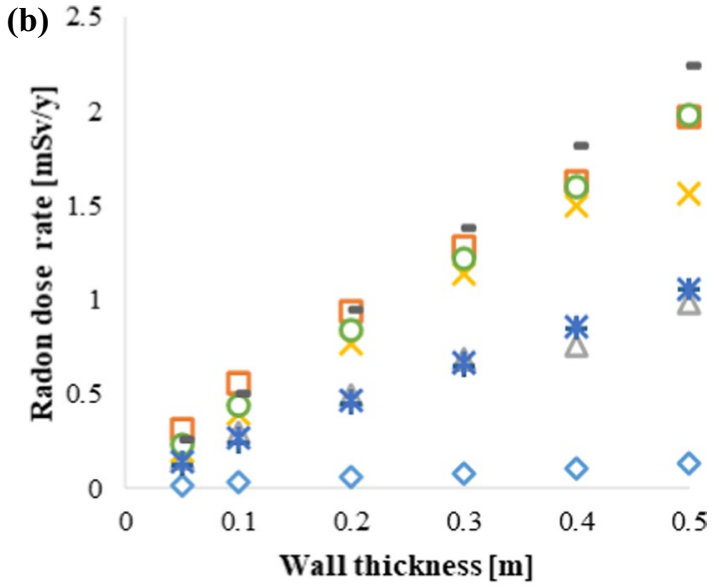

- Concrete_1 $1 \square$ Concrete_ $2 \Delta$ Concrete_ $3 \times$ Concrete_ 4
- Concrete $6+$ Concrete $7 \cdot$ Concrete $8 \times$ Concrete 5

Fig. 5 The influence of the wall thickness using the different concrete mixtures, for external dose rate $\mathbf{a}$ and radon dose rate $\mathbf{b}$

The influence of different wall thickness parameters to the external dose and to the radon dose can be seen in Fig. 5. It can be seen that the wall thickness increases the received dose. In Fig. 5a it can be seen that the external dose rate increases until the wall thickness of $0.3 \mathrm{~m}$, after that the external dose values started to decrease. This can be because after the wall thickness is greater than $0.3 \mathrm{~m}$ the addition of the wall thickness does not increase the external dose from the gamma radiation due to self-absorption. In Fig. $5 \mathrm{~b}$ it can be seen that the radon dose rate seems to have a nearly linear correlation between the wall thickness and the radon dose rate. This study presents similar results like others found in the literature, like the study presented by Koblinger in 1984 [32], this is likely to be due to the model used by the RESRAD BUILD software [26].

In this study the influence of the different room dimension parameters was investigated too. In Fig. 6a it can be seen that if we increase the room dimension from 16 to $48 \mathrm{~m}^{2}$ the external dose rate also increases. A significant increase can be seen between the data points. The radiation comes from the four walls, and larger rooms mean more material in the walls competes with increasing distances. As the room size increases, the indoor doses also increase, and vice versa. In Fig. 6b the opposite situation can be seen. In this case it can be observed that with the increased room area the radon dose rate has a constant decrease, due to the increasing volume overcoming the effect of the increasing amount of wall material. The presented result shows the similar variation between the room area and the dose rates, like study wrote by Abdullahi in 2020.

It was also investigated the relation between the total doses and the different wall thicknesses, this can be seen in Fig. 7a. With the increase of the wall thickness the total dose rate increases as well, the increased value in case of the $0.5 \mathrm{~m}$ wide wall in is approximately 4 times higher than the value for the $0.05 \mathrm{~m}$ wide wall. Moreover, it can be also seen that those concrete matrixes, like Concrete 2, 6 and 8, which contain a higher amount of high Index-I additive materials, exceeded the recommended value of $1 \mathrm{mSv} / \mathrm{y}$, even in some cases where Index-I was below 1 . The use of these concrete mixtures has to be properly evaluated, as the EU BSS suggests, Index-I is a screening 


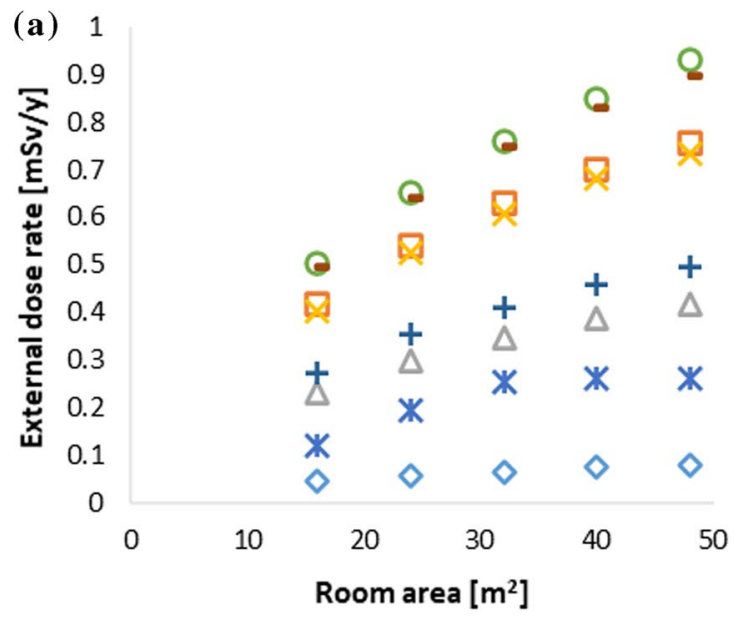

$\diamond$ Concrete_1 1 Concrete_ $2 \Delta$ Concrete_ $3 \times$ Concrete_4
$\times$ Concrete_5 0 Concrete_ $6+$ Concrete $77 \cdot$ Concrete_ 8

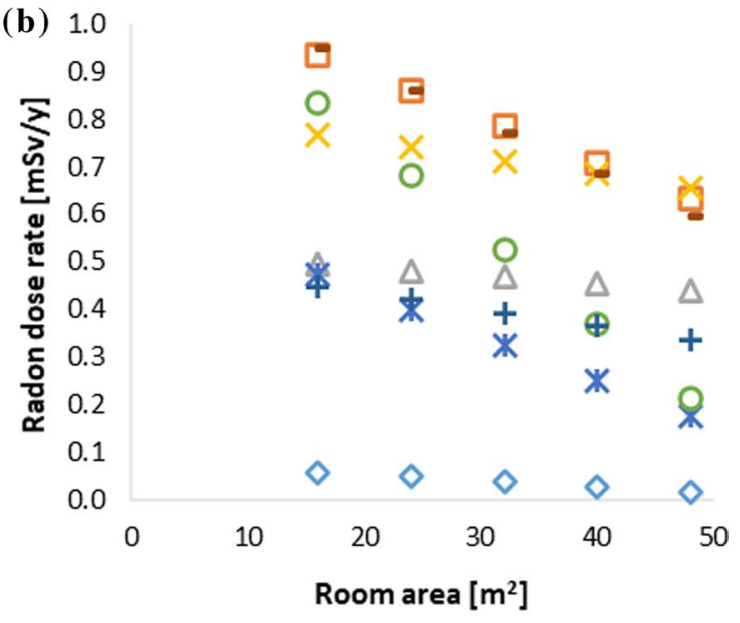

$\diamond$ Concrete_1 $\square$ Concrete_ $2 \Delta$ Concrete_ $3 \times$ Concrete_4
$\times$ Concrete_5 $\circ$ Concrete_ $6+$ Concrete_ $7 \cdot$ Concrete_ 8

Fig. 6 The influence of the room area parameters using different concrete mixtures, for external dose rate $\mathbf{a}$ and radon dose rate $\mathbf{b}$

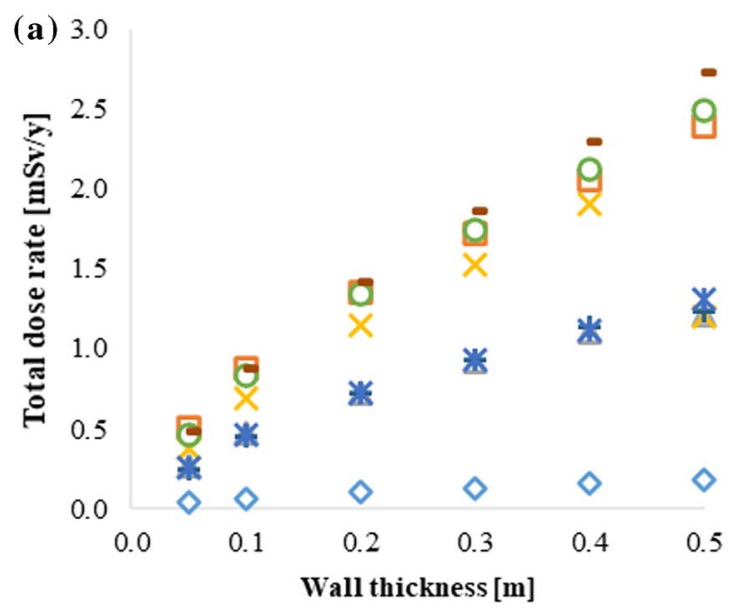

$\diamond$ Concrete_1 1 Concrete_ $2 \Delta$ Concrete_ $3 \times$ Concrete_4

- Concrete $6+$ Concrete_ $7-$ Concrete_ $8 \times$ Concrete 5

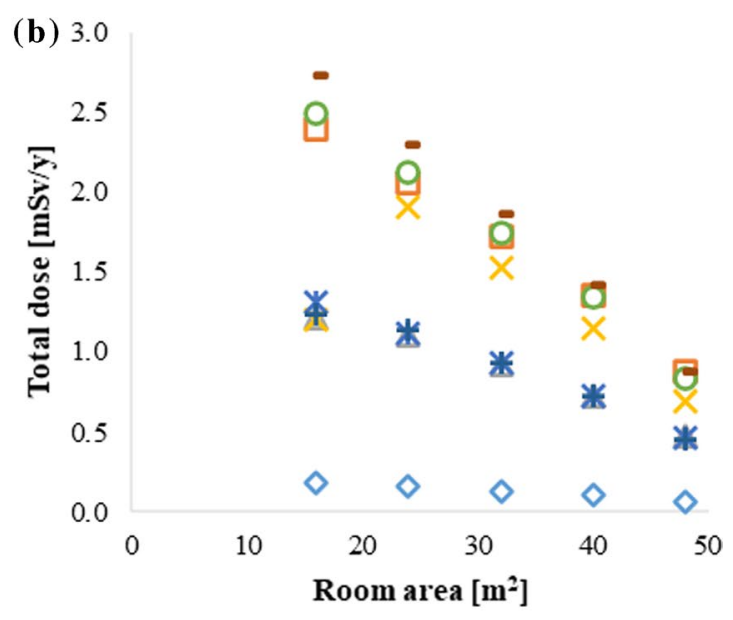

$\diamond$ Concrete_1 Concrete_2 $\triangle$ Concrete_3 $\times$ Concrete_4

$x$ Concrete_ 50 Concrete_ $6+$ Concrete_ $7 \cdot$ Concrete_ 8

Fig. 7 The influence of the different wall thickness parameters $\mathbf{a}$ and room area parameters $\mathbf{b}$ for total dose rate

tool, under different model conditions, even material that has an Index-I under 1 can cause doses over $1 \mathrm{mSv} / \mathrm{year}$. Although it can be seen that the total dose it is increasing significantly until the wall thickness of $0.3 \mathrm{~m}$, after that the increase lightly starts to smooth. The reason of this is the thickness of the wall, if the thickness is increasing the absorption of gamma-rays starts to increase too, so the dose from gamma starts to decrease. On the other hand, the radon which is one of the biggest contributors to the total dose, can easily exit from the concrete matrix if the wall is slimmer. If the wall is thicker, the relative amount of the exhaled radon will be lower. Figure $7 b$ shows the total effective dose at different room dimensions for different concrete matrixes. When the room size was increased from 16 to $48 \mathrm{~m}^{2}$ it can be seen that the total dose rate significantly decreased. 


\section{Conclusion}

Gamma ray spectrometry was used to determine the activity concentrations of Ra-226, Th-232 and K-40 in the studied samples. The obtained results were compared with other countries' results obtained for the same type of samples. The data shows us that all of the obtained results fit in the range of reported for similar materials. The exhalation and emanation rate, absorbed gamma dose rate in indoor air and the corresponding annual effective dose rate and I-index parameters were calculated to qualify and quantify the radiological hazard associated with the studied materials. It is concluded that the radiological parameters obtained in some of the samples are normal, and under the recommended limits. The annual effective dose rate varies between 0.1 and $3.6 \mathrm{mSv} /$ year. The lowest value belongs to the cement sample and the highest to the mill tailing sample. In case of the Index-I values there are two samples which exceeded the recommendation level of $1 \mathrm{mSv} / y e a r$, these are the mill tailing and the red mud samples with a value of 2.2 and 1.1 $\mathrm{mSy} / \mathrm{year}$. These materials according to the legislation can be used as construction materials in a small amount. Radium concentration and radon exhalation rates (both the mass and surface exhalation rates) have been measured successfully using an AlphaGUARD 2000 portable radon monitor. The radon exhalation study is important for understanding the relative contribution of the materials to the total radon concentration found inside the dwellings. The lowest mass and surface exhalation rates belong to the limestone sample and the highest to the mill tailing sample. From this study, a positive correlation has been observed, according to the Pearson's correlation analysis, between radium concentration and the mass and surface exhalation rate in the measured samples. Furthermore, the indoor doses attributed to each of the measured natural radionuclides were also evaluated using RESRAD-BUILD computer code. It can be seen in the result, in case of increasing the amount of some of the additives like red mud, fly ash and mill tailing the measured values like external dose rate and radon dose rate will increase too. In this case it is necessary to find the perfect amounts or ratios which can be added to the building materials, to avoid exceeding the relevant radiological screening indices. In addition to the evaluation of long-term indoor doses, the effects of wall thickness to the indoor doses based on the standard room covered with tiles were also investigated. In conclusion, it can be said that the value can vary depending on parameters such as the surface, the position of the occupant in the room, the density of the building materials, the ventilation of the room, the porosity of the wall, the emanation rate, and the diffusion coefficient. Therefore, these potential building material samples under investigation can be used in the construction of dwellings, but only in the appropriate concentrations, and it will be considered safe for inhabitants according to the relevant regulations.

Funding Open access funding provided by University of Pannonia.

Open Access This article is licensed under a Creative Commons Attribution 4.0 International License, which permits use, sharing, adaptation, distribution and reproduction in any medium or format, as long as you give appropriate credit to the original author(s) and the source, provide a link to the Creative Commons licence, and indicate if changes were made. The images or other third party material in this article are included in the article's Creative Commons licence, unless indicated otherwise in a credit line to the material. If material is not included in the article's Creative Commons licence and your intended use is not permitted by statutory regulation or exceeds the permitted use, you will need to obtain permission directly from the copyright holder. To view a copy of this licence, visit http://creativecommons.org/licenses/by/4.0/.

\section{References}

1. Kovács T, Szeiler G, Fábián F, Kardos R, Gregorič A, Vaupotič J (2013) Systematic survey of natural radioactivity of soil in Slovenia. J Environ Radioact 122:70-78. https://doi.org/10.1016/j. jenvrad.2013.02.007

2. Kardos R, Sas Z, Hegedús M, Shahrokhi A, Somlai J, Kovács T (2015) Radionuclide content of NORM by-products originating from the coal-fired power plant in Oroszlány (Hungary). Radiat Prot Dosim 167:266-269. https://doi.org/10.1093/rpd/ncv259

3. Shahrokhi A, Adelikhah M, Chalupnik S, Kocsis E, Toth-Bodrogi E, Kovács T (2020) Radioactivity of building materials in Mahallat, Iran - an area exposed to a high level of natural background radiation - attenuation of external radiation doses. Mater Constr 70(340):233. https://doi.org/10.3989/mc.2020.03820

4. Sanjuán M, Quintana B, Argiz C (2018) Coal bottom ash natural radioactivity in building materials. J Radioanal Nucl Chem 319(1):91-99. https://doi.org/10.1007/s10967-018-6251-0

5. Sanjuán MÁ, Suarez-Navarro JA, Argiz C (2021) Radiation dose calculation of fine and coarse coal fly ash used for building purposes. J Radioanal Nucl Chem 327:1045-1054. https://doi.org/10. 1007/s10967-020-07578-8

6. Hegedûs M, Sas Z, Tóth-Bodrogi E, Szántó T, Somlai J, Kovács $\mathrm{T}$ (2016) Radiological characterization of clay mixed red mud in particular as regards its leaching features. J Environ Radioact 162-163:1-7. https://doi.org/10.1016/j.jenvrad.2016.05.002

7. Kovler K, Perevalov A, Steiner V, Metzger L (2005) Radon exhalation of cementitious materials made with coal fly ash: Part 1 scientific background and testing of the cement and fly ash emanation. J Environ Radioact 82(3):321-334. https://doi.org/10.1016/j. jenvrad.2005.02.004

8. Somlai J, Jobbágy V, Kovács J, Tarján S, Kovács T (2008) Radiological aspects of the usability of red mud as building material additive. J Hazard Mater 150(3):541-545. https://doi.org/10. 1016/j.jhazmat.2007.05.004

9. Ductnan V, Kopar T (2007) The influence of different waste additions to clay-product mixtures. Mater Technol 41(6):289-293

10. Szabó Z, Völgyesi P, Nagy H, Szabó C, Kis Z, Csorba O (2013) Radioactivity of natural and artificial building materials - a comparative study. J Environ Radioact 118:64-74. https://doi.org/10. 1016/j.jenvrad.2012.11.008

11. Sas Z, Somlai J, Szeiler G, Kovács T (2015) Usability of clay mixed red mud in Hungarian building material production 
industry. J Radioanal Nucl Chem 306(1):271-275. https://doi. org/10.1007/s10967-015-3966-Z

12. Sas Z, Doherty R, Kovacs T, Soutsos M, Sha W, Schroeyers W (2017) Radiological evaluation of by-products used in construction and alternative applications; Part I. Preparation of a natural radioactivity database. Constr Build Mater 150:227-237. https:// doi.org/10.1016/j.conbuildmat.2017.05.167

13. Dodge-Wan D, Mohan VP (2021) Terrestrial gamma radiation dose rate mapping and influence of building materials: case study at Curtin University campus (Miri, Sarawak, Malaysia). J Radioanal Nucl Chem. https://doi.org/10.1007/s10967-021-07641-y

14. Coletti C, Brattich E, Cinelli G, Cultrone G, Maritan L, Mazzol C, Mostacci D, Tositti L, Sassi R (2020) Radionuclide concentration and radon exhalation in new mix design of bricks produced reusing NORM by-products: the influence of mineralogy and texture. Constr Build Mater 260:119820. https://doi.org/10.1016/j.conbu ildmat.2020.119820

15. Bahu Y, Kessongo J, Peralta L (2021) Exposure to radon in buildings in the municipality of Lubango, Angola, during winter months. J Radioanal Nucl Chem 327:635-642. https://doi.org/10. 1007/s10967-020-07570-2

16. Khan A, Rafique M, Rahman S, Kearfott KM (2016) A review of radon measurement studies with nuclear track detectors (NTDs) in Azad Kashmir. Indoor Built Environ 26(4):447-455. https:// doi.org/10.1177/1420326X15626236

17. Adelikhah M, Shahrokhi A, Chalupnik S, Tóth-Bodrogi E, Kovács $\mathrm{T}$ (2020) High level of natural ionizing radiation at a thermal bath in Dehloran. Iran Heliyon 6(7):e04297. https://doi.org/10.1016/j. heliyon.2020.e04297

18. Charles M (2001) UNSCEAR report 2000: sources and effects of ionizing radiation. J Radiol Prot 21(1):83-85. https://doi.org/10. 1088/0952-4746/21/1/609

19. Imani M, Adelikhah M, Shahrokhi A, Azimpour G, Yadollahi A, Kocsis E, Toth-Bodrogi E.Kovács T (2021) Natural radioactivity and radiological risks of common building materials used in Semnan Province dwellings, Iran. Environmental Science and Pollution Research. https://doi.org/10.1007/s11356-021-13469-6

20. Raghu Y, Ravisankar R, Chandrasekaran A, Vijayagopal P, Venkatraman B (2017) Assessment of natural radioactivity and radiological hazards in building materials used in the Tiruvannamalai District, Tamilnadu, India, using a statistical approach. J Taibah Univ Sci 11(4):523-533. https://doi.org/10.1016/j.jtusci.2015.08. 004

21. Kovács T, Shahrokhi A, Sas Z, Vigh T, Somlai J (2017) Radon exhalation study of manganese clay residue and usability in brick production. J Environ Radioact 168:15-20. https://doi.org/10. 1016/j.jenvrad.2016.07.014

22. European Union, Council Directive 2013/59/Euratom of 5 December, 2013. laying down basic safety standards for protection against the dangers arising from exposure to ionising radiation, and repealing Directives 89/618/Euratom, 90/641/Euratom, 96/29/
Euratom, 97/43/ Euratom and 2003/122/Euratom. Official J Eur Union, OJ L13, 17.01.2014 (2013) 1-73

23. Ugbede FO, Osahon OD (2021) Gamma spectrometric measurement of natural radionuclides and associated radiation hazards in soil of small-scale paddy farms along Enugu-Abakaliki express way Southeastern Nigeria. J Radioanal Nucl Chem. https://doi. org/10.1007/s10967-021-07671-6

24. EUROPEAN COMMISSION, 1999. Radiological protection principles concerning the natural radioactivity of building materials, radiation protection report - RP-112, European Commission, Luxembourg

25. Orosun MM, Ajibola TB, Akinyose FC (2021) Assessment of ambient gamma radiation dose and annual effective dose associated with radon in drinking water from gold and lead mining area of Moro North-Central Nigeria. J Radioanal Nucl Chem. https:// doi.org/10.1007/s10967-021-07644-9

26. Park S, Byon J, Ban D, Lee S, Sohn W, Ahn S (2020) Derivation of preliminary derived concentration guideline level (DCGL) by reuse scenario for Kori Unit 1 using RESRAD-BUILD. Nucl Eng Technol 52(6):1231-1242. https://doi.org/10.1016/j.net.2019.11. 032

27. Sundal AV, Henriksen H, Soldal O, Strand T (2004) The influence of geological factors on indoor radon concentrations in Norway. Sci Total Environ 328:41-53

28. Trevisi R, Leonardi F, Risica S, Nuccetelli C (2018) Updated database on natural radioactivity in building materials in Europe. $\mathrm{J}$ Environ Radioact 187:90-105. https://doi.org/10.1016/j.jenvrad. 2018.01.024

29. Kamunda C, Mathuthu M, Madhuku M (2016) An assessment of radiological hazards from gold mine tailings in the province of Gauteng in South Africa. Int J Environ Res Public Health 13(1):138. https://doi.org/10.3390/ijerph13010138

30. Trevisi R, Risica S, D'Alessandro M, Paradiso D, Nuccetelli C (2012) Natural radioactivity in building materials in the European Union: a database and an estimate of radiological significance. J Environ Radioact 105:11-20. https://doi.org/10.1016/j.jenvrad. 2011.10.001

31. Jha SK, Prusty P, Sahu A (2021) Study on radon (222Rn) emanation coefficient and mass exhalation rate from heavy minerals of high specific gravity. J Radioanal Nucl Chem. https://doi.org/10. 1007/s10967-021-07648-5

32. Koblinger L (1984) Mathematical models of external gamma radiation and congruence of measurements. Radiat Prot Dosimetry 7(1-4):227-234

33. Abdullahi S, Ismail A, Yasir M (2020) Radiological hazard analysis of Malaysia's ceramic materials using generic and RESRAD-BUILD computer code approach. J Radioanal Nucl Chem 324(1):301-315

Publisher's Note Springer Nature remains neutral with regard to jurisdictional claims in published maps and institutional affiliations. 